\title{
Energy Expenditure of Three Public and Three Home-based Active Video Games in Children
}

MONIQUE SIMONS, TNO Expertise Center Life Style; Department of Health Sciences and the EMGO Institute for Health and Care Research, Faculty of Earth and Life Sciences, VU University; Body@Work, Research Center Physical Activity, Work and Health, TNO- VU/VUmc, VU University Medical Center, the Netherlands

SANNE I. DE VRIES, TNO Expertise Center Life Style, the Netherlands

TINUS JONGERT, TNO Expertise Center Life Style; The Hague University for Applied Sciences, Center for Research and Development; Dutch Institute of Allied Health Care, the Netherlands MARIEKE W. VERHEIJDEN, TNO Expertise Center Life Style, the Netherlands

The purpose of this study was to assess the energy expenditure (EE) experienced by children when playing six active video games, which can be used in a home environment and in a public setting (e.g. game center), and to evaluate whether the intensity of playing these games can meet the threshold for moderate-intensity physical activity, which is set at an EE equivalent to three times resting metabolic rate. Children are recommended to be physically active at a moderate intensity for at least one hour a day.

Categories and Subject Descriptors: K.4.1 [Computers and Society]: Public Policy Issues-Computerrelated health issues; K.8.0 [Personal Computing]: General-Games

General Terms: Video Games, Healthcare

Additional Key Words and Phrases: Active gaming, indirect calorimetry, physical activity, exercise intensity, youth

ACM Reference Format:

Monique Simons, Sanne I. de Vries, Tinus Jongert, and Marieke W. Verheijden. 2014. Energy expenditure of three public and three home-based active video games in children. ACM Comput. Entertain. 11, 1, Article 3 (March 2014), 7 pages.

DOI: http://dx.doi.org/10.1145/2543698.2543701

\section{INTRODUCTION}

In all age groups, adequate levels of physical activity are a part of a healthy lifestyle and linked to better health outcomes (lower body mass, lower insulin levels and improved mental well-being) [Bouchard et al. 1994; HHS 1996; Ness et al. 2007; Leary et al. 2008; Jago et al. 2008; Schmalz et al. 2007]. Children are recommended to be physically active for at least one hour a day at a moderate intensity. Intensity is expressed in units of metabolic equivalents (MET), which are are multiples of resting metabolic rate, either measured or estimated. In the United States the cut-off value for moderate intensity is set at 3 METs [Bouchard et al. 1994]. Despite its health benefits few children in the Netherlands aged 4-17 years (23\%) meet the Dutch physical activity recommendations [Ness et al. 2007]. Also in other developed countries high levels of inactivity among

Author address: Drs. Monique Simons, TNO Quality of Life, P.O. Box 2215, 2301 CE Leiden, the Netherlands, P: +31 88866 6093; email: Monique.simons@tno.nl.

Permission to make digital or hard copies of part or all of this work for personal or classroom use is granted without fee provided that copies are not made or distributed for profit or commercial advantage and that copies show this notice on the first page or initial screen of a display along with the full citation. Copyrights for components of this work owned by others than ACM must be honored. Abstracting with credit is permitted. To copy otherwise, to republish, to post on servers, to redistribute to lists, or to use any component of this work in other works requires prior specific permission and/or a fee. Permissions may be requested from Publications Dept., ACM, Inc., 2 Penn Plaza, Suite 701, New York, NY 10121-0701 USA, fax +1 (212) 869-0481, or permissions@acm.org.

(C) 2014 ACM 1544-3574/2014/03-ART3 $\$ 15.00$

DOI: http://dx.doi.org/10.1145/2543698.2543701 
children have been reported [CDC 2003; Riddoch et al. 2007]. Promoting physical is therefore a key public health target [Reilly and McDowell 2000].

A new generation of video games has emerged; games that require physical activity to play them, the so-called "active games." In active video games the gross body movement component replaces the largely sedentary hand controller of traditional video games, which only requires small finger and wrist movements. The player has to make, for example, boxing, tennis or dancing movements to play the game. Examples of active games are Microsoft Kinect; PlayStation2 EyeToy and Move (Sony); Dance Dance Revolution (Konami); and the Nintendo Wii (Nintendo). If sedentary behavior, like playing traditional non-active video games, could be substituted with active pastime, like playing active video games, this could lead to a reduction in sedentary pastime and an increase in physical activity. Active gaming might therefore be a useful tool in helping children to meet the physical activity guideline.

A key question is whether the intensity of playing active video games is sufficient to contribute to meeting the physical activity guideline. Several studies have been conducted on energy expenditure (EE) as a measure of intensity of active video games. These studies showed that the active games Dance Dance Revolution (DDR), Nintendo Wii, PlayStation2 and EyeToy substantially increased EE compared to resting values and sedentary behavior [Tan et al. 2000; Lanningham-Foster et al. 2006; Graves et al. 2007; Maddison et al. 2007]. Whether or not active gaming is intense enough to contribute toward the international physical activity guideline depends on the type of active game. Playing Wii was found to be not intense enough to contribute toward meeting the guideline [Graves et al. 2007]. DDR, on the other hand, did show a sufficient intensity to meet the physical activity guideline [Tan et al. 2000]. However, they included college students (mean age $=17.5$ year) and applied the guideline for adults [Leary et al. 2008].

The evidence thus far was obtained focused primarily on consoles and games that are targeted for use in a home environment (e.g. Nintendo Wii, PlayStation2, and EyeToy) [Tan et al. 2000; Lanningham-Foster et al. 2006; Graves et al. 2007]. Besides these home use active games, there are also active games that are not suitable for home use. Because of their size and the price, they are only suitable for public use. Examples of those games are Exerbike, Lasersquash, and Apartgame (see Box 1. for a description of these active games). These games are too big to be placed in a bedroom or a living room, but they are very suitable for a public setting, like a school or an entertainment center. Also these games are very expensive to buy as an individual for private use (prices range from $\$ 3000$ to $\$ 6000$ ). Public settings can be very relevant for stimulating physical activity among children [Naylor et al. 2009]. In their research, Ridley and Olds focused on public setting and evaluated children's EE while playing in a video games center [2001]. For table hockey and a mini basketball shooting game, they found an energy expenditure of approximately 3 METs and for Final Furlong (a horse-racing game) approximately 6 METs. The problem with traditional video game centers is that there are also many sedentary games available and these games are more popular than active video games [Ridley 2001]. To the best of our knowledge, the EE of active video games that are developed for use in other public settings like schools, sport halls, fitness clubs has not yet been quantified.

Therefore, the aim of the current study was (1) to assess the EE of three publicoriented active consoles and compare it with the EE of three home-use oriented active consoles in children aged 7-13 years old; and (2) to determine whether the intensity of these games is sufficient to meet current physical activity guidelines.

\section{METHODS}

A convenience sample of six boys and six girls aged 7-13 years participated in the study. The children were recruited at a primary school in the Netherlands. Children were 
screened using a questionnaire based on the Physical Activity Readiness Questionnaire (PAR-Q) [Reading et al. 1992] to exclude children with medical conditions, physical disabilities or injuries that would interfere with playing the games. Written informed consent was obtained from the children and their parents.

Six games were selected based on a criteria list formulated by the researchers [van den Boogaard et al. 2007]. Some of the criteria used were: ease of play, price, diversity of game level, and competition element. The six games that scored best on these criteria were Xerbike, Lasersquash, Apartgame, DDR, Wii Tennis, and EyeToy-beach volleyball (see Box 1).

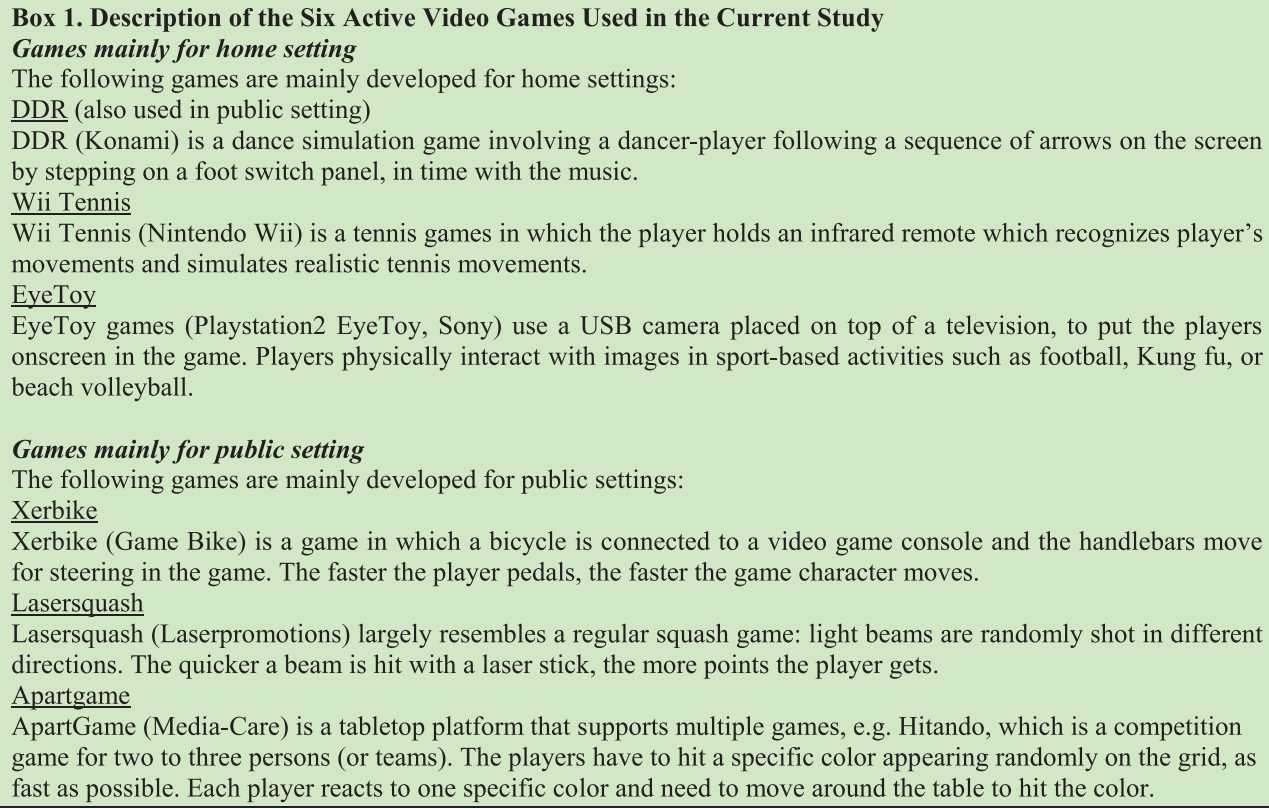

The study took place in June 2007 in a sport hall where the video games were temporarily installed. Participating children came to the sport hall two by two. Body height $(\mathrm{cm})$ and weight $(\mathrm{kg})$ were measured using standardized protocols [Fredriks et al. 2002]. First the children were told how the games worked, and then they were allowed to try the games to get familiarized. This lasted about 15 minutes after which the children rested for at least 10 minutes before the measurement started. For the oxygen consumption measurement children were equipped with a portable indirect calorimetry gas-exchange analysis system (Cortex Vmax ST) [Harrell et al. 2005]. The children wore a face covering their nose and mouth. As was done in previous research [Maddison et al. 2007; Ridley 2001], measurements were averaged over 15 seconds and lasted five minutes for each game. The mean readings of the last four minutes were taken as the steady-state oxygen consumption $\left(\mathrm{VO}_{2}\right)$. VO2 was standardized by body weight by dividing through kilogram bodyweight and expressed in amount of milliliters consumed per kilogram of bodyweight per minute $(\mathrm{ml} / \mathrm{kg} / \mathrm{min})$. Simultaneously children were equipped with a Polar heart-rate monitor (Polar Electro Oy). Intensity was expressed in METs, and calculated by dividing the $\mathrm{VO}_{2}$ per kilogram of bodyweight measured during the active games by the child specific resting oxygen uptake of $5,92 \mathrm{ml} / \mathrm{kg} / \mathrm{min}$ for 8-12 years old boys and 8-11 years old girls; or $4.58 \mathrm{ml} / \mathrm{kg} / \mathrm{min}$ for $13-15$ years old boys and 12-14 years old girls [Harrell et al. 2005]. Estimated relative intensity was determined using heart rate expressed as percentage of maximal heart rate (HRmax), 
Table I. Descriptive characteristics of study population (mean (SD) unless mentioned otherwise)

\begin{tabular}{lc}
\hline Characteristics & $(\mathrm{n}=12)$ \\
\hline Age, year & $10.3(2.0)$ \\
Gender, male \% & 50 \\
Height, mean (SD) $m$ & $1.45(0.10)$ \\
Weight, $\mathrm{kg}$ & $37.4(9.1)$ \\
$\mathrm{BMI}, \mathrm{kg} / \mathrm{m}^{2}$ & $17.5(3.1)$ \\
$\mathrm{BMI}^{*}$, underweight/normal/overweight $n$ & $2 / 8 / 2$ \\
\hline
\end{tabular}

*Based on sex and age specific cut-off values by Buuren van 2004 (underweight cut-off), and Cole et al., 2000 (overweight cut off).

Table II. Exercise intensity in VO2, METs, HR, \%HRmax and number of children reaching the cut-off value for moderate-intensity for the six active video games (mean (SD) unless mentioned otherwise)

\begin{tabular}{lccccc}
\hline & & & & & $\begin{array}{c}\text { Number of children } \\
\text { reaching } \geq 3 \text { METs } \\
\left(\mathrm{n}_{\text {total }}=12\right)\end{array}$ \\
Game & VO2 $(\mathrm{ml} / \mathrm{kg} / \mathrm{min})$ & METs & HR $(\mathrm{bpm})$ & $\%$ HRmax & 4 \\
\hline Wii Tennis & $15,3(3,8)$ & $2,7(0,6)$ & $119(10)$ & $62 \%$ & 4 \\
EyeToy - beach volleyball & $16,5(4,5)$ & $2,9(0,6)$ & $123(10)$ & $64 \%$ & 8 \\
DDR & $18,3(3,9)$ & $3,2(0,6)$ & $126(11)$ & $65 \%$ & 12 \\
ApartGame & $32,0(6,2)$ & $5,6(1,0)$ & $164(17)$ & $85 \%$ & 12 \\
Lasersquash & $32,6(6,2)$ & $5,7(1,4)$ & $169(14)$ & $88 \%$ & 11 \\
Xerbike & $34,4(8,0)$ & $6,1(1,4)$ & $164(15)$ & $88 \%$ & \\
\hline
\end{tabular}

using an estimated maximal heart rate for children (independent of age) of 193 per minute [Takken et al. 2007].

The games were played in two series of three in a fixed order based on the intensity measured on a test day. Series one consisted of EyeToy (beach volleyball, level beginners); ApartGame (Hitando, two players); and Lasersquash (adult mode, level hard, two players). Series two consisted of Wii (tennis, best of five); DDR (level easy and beginners, using the songs "All the Things She Said" by t.A.T.u., "Biology" by Girls Aloud, "Bruised" by The Sugababes, and "Hey Boy, Hey Girl" by The Chemical Brothers); and Xerbike (Versus/Roadrace/Radiator Springs, two players). Within the series, children started with the lowest intensity game and ended with the highest intensity game. After each game a rest period of 2-5 minutes took place to allow heart rate and $\mathrm{VO}_{2}$ return to normal levels. In between the two series the children had a longer rest period of 15 minutes.

\section{RESULTS}

The descriptive characteristics of the participating children are shown in Table I. Most $(n=8)$ children had a normal weight according to the sex and age specific cut-off values for underweight [van Buuren et al. 2004] and overweight [Cole et al. 2000]. The group consisted of an equal amount of boys and girls and ages ranged from 7 through 13 years.

Table II shows mean EE, expressed in $\mathrm{ml} / \mathrm{kg} / \mathrm{min}$ and estimated MET values. Further, mean $\mathrm{HR}$ and $\% \mathrm{HR}_{\max }$ values are shown in Table II. The highest EE was found in playing Lasersquash and Xerbike (5.7 and 6.1 METs respectively). The lowest EE was found for Wii Tennis (2.7 METs). Heart rate expressed as a percentage of the estimated maximum ranged from $62 \%$ to $88 \%$ and showed the same pattern as the MET values.

\section{DISCUSSION}

EE of the public based games (Apartgame, Lasersquash, Xerbike) and DDR (both home and public based) were sufficiently high to meet the threshold for moderate intensity 
physical activity ( $\geq 3 \mathrm{METs}$ ). And in this way these active games can contribute to meeting the international physical activity guideline for children.

For Apartgame, Lasersquash and Xerbike the current study was the first to assess EE. The EE of DDR, Eye Toy and Wii were also evaluated in previous studies. The previous studies [Tan et al. 2000; Lanningham-Foster et al. 2006; Maddison et al. 2007 showed comparable values for active dance games $(\approx 2.7,3.9$ and 3.4 METs respectively). In the current study, the average intensity of playing EyeToy beach volleyball was 2.9 METs. The metabolic cost of performing other EyeToy games, namely Knockout, Homerun, Dance UK, Groove and AntiGrav, typically ranges between 2.3 and 5.0 METs [Maddison et al. 2007].

A limitation of the current study is the small and select sample. The small sample size is comparable with that in the study of Graves et al. [2007], but was lower than in other studies [Tan et al. 2000; Lanningham-Foster et al. 2006; Maddison et al. 2007]. The study population was limited to 7-13 year old children. Future studies should therefore include a larger and a more varied sample of children for generalization of the results. Also the short familiarization period could have influenced the results. The study of Sell et al. showed that energy expenditure of playing an active game depended on play experience [2008]. Participants with greater playing experience could work at higher intensities, promoting greater energy expenditure [Sell et al. 2008]. Another limitation is the short measurement period. The children were measured for only a five-minute game. Future studies should examine active gaming in a more real-life setting and should focus on (1) whether EE is also sufficient when playing active video games for a longer period of time and (2) whether children are motivated to play the active video games for a sustainable period of time.

In addition to EE also frequency and duration of use [Janssen et al. 2007; Kemper et al. 2000] are important factors for determining whether active video games can serve as a tool to contribute to meeting the physical activity guidelines. Therefore in the current study, enjoyment and appreciation of these six active video games were also evaluated in a qualitative way in a partly overlapping study population by means of observations and group interviews [van den Boogaard et al. 2007]. In the group interviews many children reported to like Lasersquash and Exerbike most. Aspects that determined whether or not the children liked a game were: type and intensity of movement, novelty factor, difficulty, challenge, and sensitivity of the interface of the game. Almost all children indicated that they would visit a game hall with active games. Studies that have been conducted on motivation for longer-term (home) use in children to play active video games showed that motivation is an important point of concern [Chin et al. 2008; Madsen et al. 2007]. Frequency and duration of playing active video games can decrease substantially in a short period [Chin et al. 2008; Madsen et al. 2007]. More research is necessary to evaluate how children can be stimulated to play active video games for a sustainable period.

Another important question is whether risk groups-such as inactive children, children who are overweight, and children with a low socio-economic status (SES) — can be reached with active video games. Finally, it should be investigated which settings (home-based, school, local facilities in the neighborhood, sports/fitness hall, after school or child care) are most appropriate for implementing active video games.

\section{CONCLUSION}

Mean EE of the three public setting video games (Exerbike, Lasersquash, Apartgame) and DDR (appropriate for home and public setting) was shown to be sufficiently high to meet the threshold for moderate intensity physical activity ( $\geq 3$ METs). 
The results suggest that especially active video games targeted for public settings may be successful in promoting health enhancing physical activity among children aged 7 to 13 years old.

\section{ACKNOWLEDGMENTS}

We kindly thank Innosport Brabant and municipal authority of Eindhoven for funding the study. We are grateful to sports centre Eindhoven North for providing space in a sport hall for installing the video games. Next, we want to thank Melvin Kantebeen from ConTest for executing the oxygen measurements measurements as well as research assistant Caroline van den Boogaard. The authors acknowledge the school and the participants for their cooperation in this study and the game producers for providing the video games. The authors declare that there are no conflicts of interest.

\section{REFERENCES}

Boogaard van den, C. M. H., Vries de, S. I., and Simons, M. et al. 2007. Exercising with video games. Leiden, TNO Kwaliteit van Leven. (In Dutch).

Bouchard, C., Shephard, R. J., and Stephens, T. 1994. Physical activity, fitness, and health: International proceedings and consensus statement. Champaign, Illinois: Human Kinetics Publishers.

Buuren van, S. 2004. Body-mass index cut-off values for underweight in Dutch children. Ned Tijdschr Geneesk 40, 1967-72.

Centers for Disease Control and Prevention. 2003. Physical activity levels among children aged 9 -13 years: United States, 2002. MMWR Morb Mortal Wkly Rep. 52, 33, 785-788.

Chin, A., Paw, M. J. M., Jacobs, W. M., and Vaessen, E. P. G. et al. 2008. The motivation of children to play an active video game. J Sci Med Sport 11, 163-166.

Cole, T. J., Belizzi, M. C., and Flegal, K. M. et al. 2000. Establishing a standard defenition for child overweight and obesity worldwide: international survey. BMJ 320, 1-6.

Fredriks, A. M., Buuren van, S., and Burgmeijer, R. J. F. et al. 2002. Growth diagrams: manual for height en weight measurements in children and filling in growth diagrams. TNO/ LUMC, Leiden; (in Dutch).

Graves, L., Stratton, G., and Ridgers, N. D. et al. 2007. Energy expenditure in adolescents playing new generation computer games. Br J Sports Med 7, 592-4.

Harrell, J. S., McMurray, R. G., and Baggett, C. D. et al. 2005. Energy cost of physical activities in children and adolescents. Med Sci Sports Exercise 37, 2, 329-336.

Jago, R., Wedderkopp, N., Kristensen, P. L., Moller, N. C., Andersen, L. B., Cooper, A. R., and Froberg, K. 2008. Six-year change in youth physical activity and effect on fasting insulin and HOMA-IR. Am J Prev Med, 35, 6, 554-560.

Janssen, I. 2007. Physical activity guideline for children and youth. Applied Physiology, Nutrition, and Metabolism 32, 109-121.

Kemper, H. G. C., Ooijendijk, W. T. M., and Stiggelbout, M. 2000. Consensus on the Dutch physical activity guideline. TSG 78, 180-183. (In Dutch).

Lanningham-Foster, L., Jensen, T. B., and Foster, R. C. et al. 2006. Energy expenditure of sedentary screen time compared with active screen time for children. Pediatrics 118, e1831-e1835.

Leary, S. D., Ness, A. R., Smith, G. D., Mattocks, C., Deere, K., Blair, S. N., and Riddoch, C. 2008. Physical activity and blood pressure in childhood: findings from a population-based study. Hypertension 51, 1 , 92-98.

Maddison, R., Mhurchu, C. N., and Jull, A. et al. 2007. Energy expended playing video console games: an opportunity to increase children's physical activity? Pediatric Exercise Science 19, 334-343.

Madsen, K. A., Yen, S., and Wlasiuk, L. et al. 2007. Feasibility of a dance videogame to promote weight loss among overweight children and adolescents. Arch Pediatr Adolesc Med 161, 105-7.

Naylor, P. J. and McKay, H. A. 2009. Prevention in the first place: schools as a setting for action on physical activity. Br J Sports Med 43, 10-13.

Ness, A. R., Leary, S. D., Mattocks, C., Blair, S. N., Reilly, J. J., Wells, J., Ingle, S., Tilling, K., Smih, G. D. and Riddoch, C. 2007. Objectively measured physical activity and fat mass in a large cohort of children. PLOS Medicine 4, 3.

Ooijendijk, W. T. M., Hildebrandt, V. H., and Chorus, A. M. J. 2008. Physical activity in the Netherlands. In: Monitoring physical activity and health. Eds: Hildebrandt, V. H., Ooijendijk, W. T. M., Hopman-Rock, M. De Bink, Leiden. 9-42. (In Dutch). 
Reading, T. S. and Shephard, R. J. 1992. Revision of the physical activity readiness questionnaire (PAR-Q). Can J Sport Sci 17, 338-345.

Reilly, J. J. and McDowell, Z. C. 2000. Physical activity interventions in the prevention and treatment of paediatric obesity: Systematic review and critical appraisal. Proc Nutr Soc. 62, 3, 611-9.

Riddoch, C. J., Mattocks, C., Deere, K., Saunders, J., Kirkby, J., Tilling, K., Leary, S. D., Blair, S. N., and Ness, A. R. 2007. Objective measurement of levels and patterns of physical activity. Arch Dis Child 92, 11, 963-969.

Ridley, R. and Olds, T. 2001. Video Center Games: Energy cost and children's behaviors. Pediatric Exercise Science 13, 413-421.

Sell, K., Lillie, T., and Taylor, J. 2008. Energy expenditure during physically interactive video game playing in male college students with different playing experience. J Am Coll Health. Mar-Apr 56, 5, 505-11.

Schmalz, D. L., Deane, G. D., Birch, L. L., and Davison, K. K. 2007. A longitudinal assessment of the links between physical activity and self-esteem in early adolescent non-Hispanic females. $J$ Adolesc Health, $41,6,559-565$.

Takken, T. and Hulzebos, E. H. J. 2007. Exercise physiology in children. Sport \& Geneeskunde 1, 24-32. (In Dutch).

Tan, B., Aziz, A. R., and Chua, K. et al. 2000. Aerobic demands of the dance simulation game. Int J Sports Med 2, 125-9.

U. S. Department of Health and Human Services (HSS), 1996. 